\title{
The Study on Activity Enhancement of Gold and Palladium Alloy Nanoparticles in Comparison with Monometallic Catalysts
}

\author{
Wenjing Cui a, Xiaolei Zhang ${ }^{b}$, Jinjin Lu ${ }^{c}$, Gentuya Meng ${ }^{d}$, Hongliang Wang ${ }^{e}$ \\ and Wei Hou *
}

\begin{abstract}
Department of Chemical Engineering, Inner Mongolia Vocation college of Chemical Engineering, Hohhot, Inner Mongolia, 010070, China
\end{abstract}

azczcwj@sina.com, b23921430@qq.com, c282145111@qq.com,

dnhymgty@126.com, e13848514517@139.com, *Corresponding Author: nhyhw@126.com

\begin{abstract}
Keywords: gold and palladium, alloy nanoparticles, activity enhancement, charge heterogeneity.
\end{abstract}
\begin{abstract}
Alloy nanoparticles (NPs) of gold and palladium were found to be more active in oxidation of benzyl alcohols than supported gold or supported palladium NPs. The enhanced activity of benzyl alcohol oxidation at the surface of the alloy NPs can be explained by the charge heterogeneity. To confirm the charge heterogeneity, simulations using the Density function theory (DFT) were carried out. TEM, EDX, UV-Vis and XPS were also employed to investigate the properties of the gold and palladium alloy NPs as well as gold, palladium monometallic catalysts.
\end{abstract}

\section{Introduction}

Supported gold catalysts draw widely attention because they showed extraordinary catalytic, selective, non-toxic and recyclable properties in many reactions. Nowadays, a variety of Au-Pd alloy catalysts show superior activity in a number of reactions compared with supported gold catalysts [1]. According to literatures, this improved activity can be caused by two effects: ensemble and ligand effects [2]. The ensemble effect is a dilution of surface Pd by Au. As the surface ratio of Au-Pd increases, the more active component $(\mathrm{Pd})$ is separated by the less active component ( $\mathrm{Au}$ ) [3]. The reaction rate is enhanced due to formation isolated $\mathrm{Pd}$ which is the active site of the reaction. The ligand effect is electronic perturbation of $\mathrm{Pd}$ by $\mathrm{Au}$. Au usually gains s, p electrons but loses 5d electrons while Pd loses s, p electrons but gains d electronic. This factor can be another reason that accounts for the activity enhancement.

Selective oxidation of alcohols to their corresponding aldehydes is of great interest in organic synthesis [4]. Aldehydes are largely acquired as they are valuable intermediates for the pharmaceuticals and agrochemicals industries [5]. Interest in catalytic oxidation of alcohols by supported gold and gold-palladium alloy nanoparticles has expanded dramatically [6].

In our study, supported Au-Pd alloy nanoparticles as well as Au NPs and Pd NPs were synthesized by the same method. The catalytic activity of benzyl alcohol oxidation on both alloy nanoparticles (NPs) and monometallic NPs were examined. The activity was largely enhanced on alloy NPs in comparison with on gold or palladium monometallic NPs. Furthermore, charge heterogeneity simulated by the Density function theory (DFT) was carried out to explain the improvement.

\section{Experimental}

\subsection{Catalyst preparation.}

$\mathrm{Au}-\mathrm{Pd} / \mathrm{ZrO}_{2}$ catalysts were prepared according to the literature [7]. $\mathrm{ZrO}_{2}$ powder $1.0 \mathrm{~g}$ was

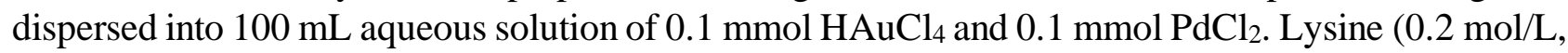
$20 \mathrm{~mL}$ ) was then added to the mixture under vigorous stirring for $30 \mathrm{~min}$. An aqueous solution of $\mathrm{NaBH}_{4}(0.1 \mathrm{~mol} / \mathrm{L}, 10 \mathrm{~mL})$ was added gradually in about $10 \mathrm{~min}$ to the suspension, followed by hydrochloric acid $(0.1 \mathrm{~mol} / \mathrm{L}, 10 \mathrm{~mL})$. The mixture was left to stand for $24 \mathrm{~h}$ and then the solid was separated, washed with water and ethanol, and dried at $80{ }^{\circ} \mathrm{C}$ for $12 \mathrm{~h}$. Preparation of $\mathrm{Au} / \mathrm{ZrO}_{2}$ or 
$\mathrm{Pd} / \mathrm{ZrO}_{2}: \mathrm{ZrO}_{2}$ powder $1.0 \mathrm{~g}$ was dispersed in $100 \mathrm{~mL}$ aqueous solution of $0.15 \mathrm{mmol} \mathrm{HAuCl}_{4}$ or 0.28 $\mathrm{mmol} \mathrm{PdCl}_{2}$. The following procedures were kept identical.

\subsection{Catalytic experiments}

The selective oxidation reactions of benzyl alcohols were carried out in a $25 \mathrm{~mL}$ round-bottomed flask with magnetic stirrer. $50 \mathrm{mg}$ catalyst, benzyl alcohol $(3 \mathrm{mmol})$ and ethanol $(10 \mathrm{~mL})$ were charged into the flask which was open to ambient air. The suspension was stirred magnetically at $40{ }^{\circ} \mathrm{C}$. During the reactions $0.1 \mathrm{ml}$ specimens were periodically collected, filtered and analyzed by GC (Shimadzu GC-2014) with a capillary column of Rtx-5, temperature of column range from 100 to $220{ }^{\circ} \mathrm{C}\left(6{ }^{\circ} \mathrm{C}\right.$ /min), injector temperature $260^{\circ} \mathrm{C}$ and flame ionization detector. The products were identified by comparison with known standard samples.

\subsection{Catalyst characterization.}

Transmission electron microscopy (TEM) images were recorded with a Jeol JEM-1210 transmission electron microscope employing an accelerating voltage of $200 \mathrm{kV}$. The samples were suspended in ethanol and dried on holey carbon-coated $\mathrm{Cu}$ grids. The composition of some samples was determined by using the energy-dispersive X-ray (EDX) spectroscopy attachment of the transmission electron microscope. The X-ray photoelectron spectroscopy (XPS) was measured with ESCALAB210 of British VG Company. All binding energies were referenced to the $\mathrm{C}$ (1s) hydrocarbon peak at $285.00 \mathrm{eV}$. UV-vis spectra were recorded on a Shimadzu UV-2550 spectrophotometer in the range of 200-800 $\mathrm{nm}$ at room temperature with $\mathrm{BaSO}_{4}$ as the reference.

\section{Results and discussion}

\subsection{Benzyl alcohol oxidation.}

As can be seen from Table 1, the Au-Pd alloy NPs exhibited superior catalytic activity to pure monometallic NPs as well as the mechanical mixture of AuNPs and PdNPs. The significant enhancement of the catalytic activity can be explained by the electronic heterogeneity of alloy NPs, which means that interactions between the alloy NPs and reactant molecules can be enhanced compared with pure Au and Pd NPs.

Given that the electronegativity of $\mathrm{Pd}$ (2.20) is different from that of $\mathrm{Au}$ (2.54) there will be a charge heterogeneity at the alloy NP surface, with both electron-rich sites and slightly positively charged sites present. The significant enhancement of the catalytic activity can be explained by the electronic heterogeneity, which means that interactions between the alloy NPs and reactant molecules can be enhanced.

Table 1. Oxidation of benzyl alcohol to benzaldehyde on different catalysts

\begin{tabular}{|c|c|c|c|c|}
\hline Catalyst & $\mathrm{Au}-\mathrm{Pd} / \mathrm{ZrO}_{2}$ & $\begin{array}{c}\mathrm{Au} / \mathrm{ZrO}_{2} \text { mixed } \\
\text { with } \mathrm{Pd} / \mathrm{ZrO}_{2}\end{array}$ & $\mathrm{Au} / \mathrm{ZrO}_{2}$ & $\mathrm{Pd} / \mathrm{ZrO}_{2}$ \\
\hline yield $(\%)$ & 88 & 33 & 16 & 43 \\
\hline
\end{tabular}

Reaction condition: benzyl alcohol (3 mmol); ethanol (10 mL); catalyst (50 mg);

$40{ }^{\circ} \mathrm{C} ; 7 \mathrm{~h}$; air atmosphere;

\subsection{The study on charge heterogeneity.}

To confirm the charge heterogeneity at the surface of the alloy NPs, simulations using the Density function theory (DFT) were carried out. Calculation capacity limitations of our DFT simulation necessitated the examination of an $\mathrm{Au}_{32}$ and $\mathrm{Au}_{12} \mathrm{Pd}_{20}$ cluster as a first step and the charge distributions of the cluster was simulated. The results of the calculation confirm that charge heterogeneity exists even in the monometallic Au clusters and the alloy structure of Au with Pd increases the charge heterogeneity of the nanoparticle surface, as can be seen from the comparison of two lines in Fig 1. Considering the electronegativity of the two metals, this charge distribution is to be expected and in agreement with previous reports [8]. 

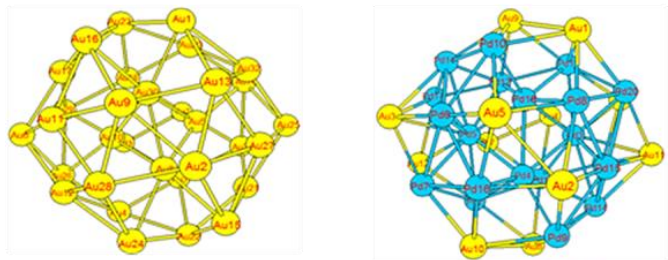

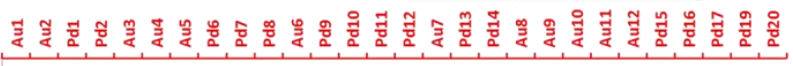

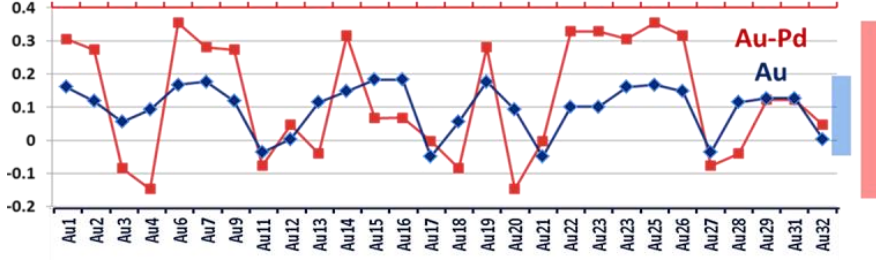

Fig. 1 The optimized geometry of the Au32 and Au12Pd20 clusters and the natural charge distribution

\subsection{Characterization of catalyst.}

calculated by DFT.

In order to get information of the eventual state of $\mathrm{Au}$ and $\mathrm{Pd}$ on the surface of the catalyst, $3 \mathrm{wt} \%$ $\mathrm{Au}-\mathrm{Pd} / \mathrm{ZrO}_{2}$ was measured by $\mathrm{X}$-ray photoelectron spectroscopy (XPS). The $\mathrm{Au}$ (4f) X-ray photoelectron spectroscopy (Fig. 2a) is consisted of two peaks at about $84.3 \mathrm{eV}$ and $87.9 \mathrm{eV}$ which corresponded to $\mathrm{Au} 4 \mathrm{f} 7 / 2$ and $\mathrm{Au} 4 \mathrm{f5} / 2$ respectively. The values were higher than that of metallic gold $\left(\mathrm{Au}^{0}, 84.0 \mathrm{eV}\right.$ and $\left.87.7 \mathrm{eV}\right)$. In Fig. 2b, the two peaks at $340.1 \mathrm{eV}$ and $334.9 \mathrm{eV}$ were $\mathrm{Pd} 3 \mathrm{~d} 3 / 2$ and $\mathrm{Pd}$ $3 \mathrm{~d} 5 / 2$ respectively, which were lower than that of $\mathrm{Pd}^{0}(340.3 \mathrm{eV}$ and $335.0 \mathrm{eV})$. It suggested that there was a strong electron interaction between $\mathrm{Pd}$ and $\mathrm{Au}$ by charge transfer.
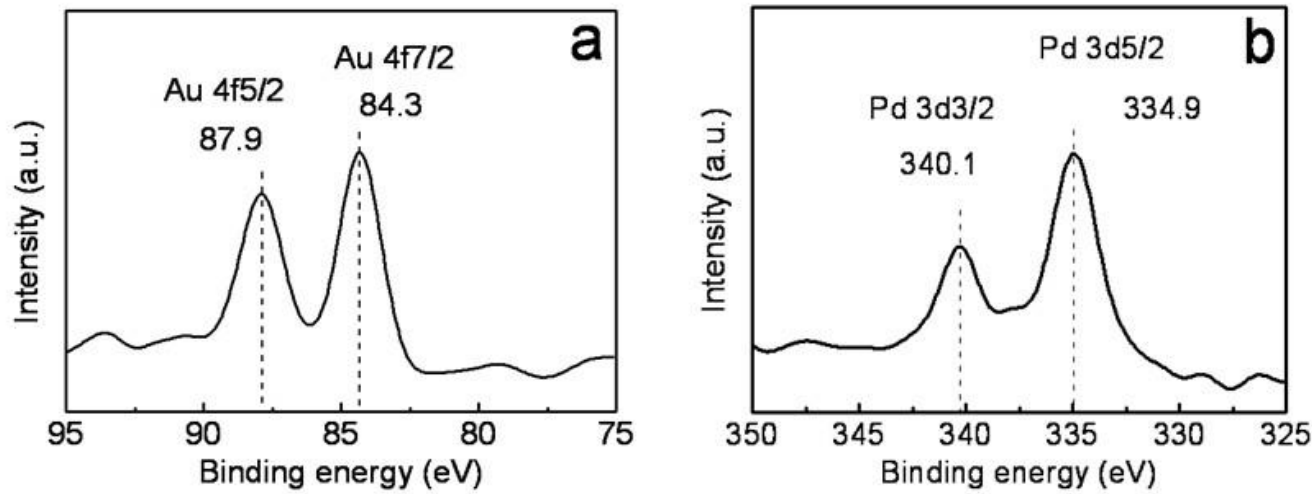

Fig. $2 \mathrm{X}$-ray photoelectron spectrum (XPS) of (a) $\mathrm{Au} 4 \mathrm{f}$ (b) $\mathrm{Pd} 3 \mathrm{~d}$ in $3 \mathrm{wt} \% \mathrm{Au}-\mathrm{Pd} / \mathrm{ZrO}_{2}$

The particle size and morphology of $\mathrm{Au} / \mathrm{ZrO} \mathrm{O}_{2}, \mathrm{Pd} / \mathrm{ZrO}_{2}$ monometallic catalysts and $\mathrm{Au}-\mathrm{Pd}$ alloy NPs can be observed by transmission electron microscopy. (Fig. 3) As it can be seen, the Au, Pd monomertallic NPs and Au-Pd alloy NPs disperse well on the $\mathrm{ZrO}_{2}$ and have mean dimensions of about $4.6 \mathrm{~nm}, 5.0 \mathrm{~nm}$ and $2.5 \mathrm{~nm}$, respectively. The alloy NPs are smaller than monometallic NPs, suggesting the chemical combination of $\mathrm{Au}$ and $\mathrm{Pd}$ to form the alloy nanoparticles rather than physical combination.
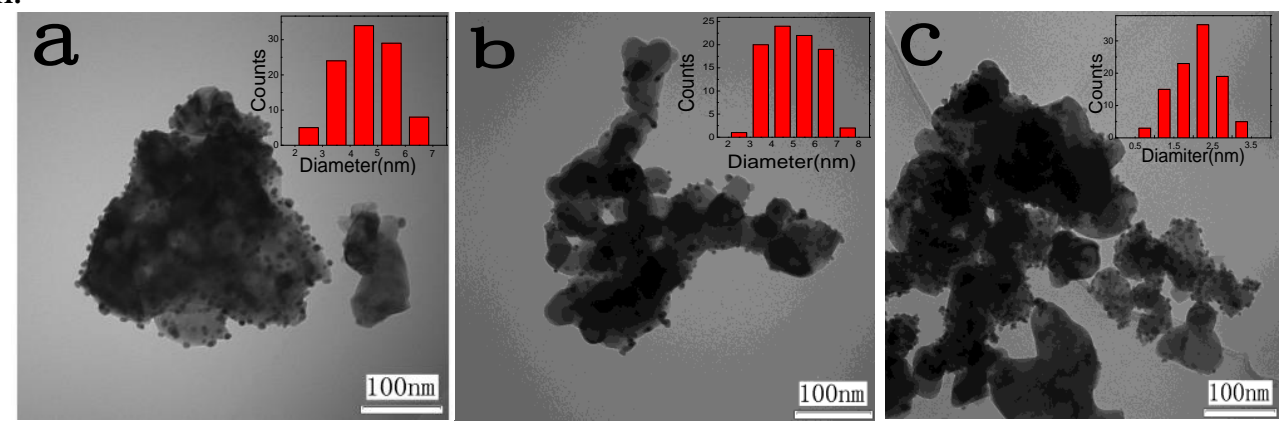

Fig.3 TEM images of (a) $3 \mathrm{wt} \% \mathrm{Au} / \mathrm{ZrO}_{2}$, (b) $3 \mathrm{wt} \% \mathrm{Pd} / \mathrm{ZrO}_{2}$ and (c) $3 \mathrm{wt} \% \mathrm{Au}-\mathrm{Pd} / \mathrm{ZrO}{ }_{2}$ catalysts with corresponding nanoparticles size distributions 
The diffuse reflectance UV spectra of $\mathrm{Au} / \mathrm{ZrO}{ }_{2}, \mathrm{Pd} / \mathrm{ZrO}_{2}$ and $\mathrm{Au}-\mathrm{Pd} / \mathrm{ZrO}_{2}$ catalysts are given in Fig. 4. The monometallic Au catalyst exhibited an absorption peak at $520 \mathrm{~nm}$ due to surface plasmon resonance (SPR), a characteristic of the gold nanoparticles. However, there is no apparent absorption band of the monometallic Pd catalyst. In the spectrum of the alloy sample, the characteristic Au NP SPR absorption peak at $520 \mathrm{~nm}$ is much weaker, when compared to the spectrum of the pure Au sample but more intense than the absorption observed for pure Pd sample. The spectrum of Au-Pd NPs shows clear difference between the spectra of the pure Au NPs and Pd NPs. It can be interpreted as the formation of Au-Pd alloy nanoparticles rather than segregated monometallic NPs.

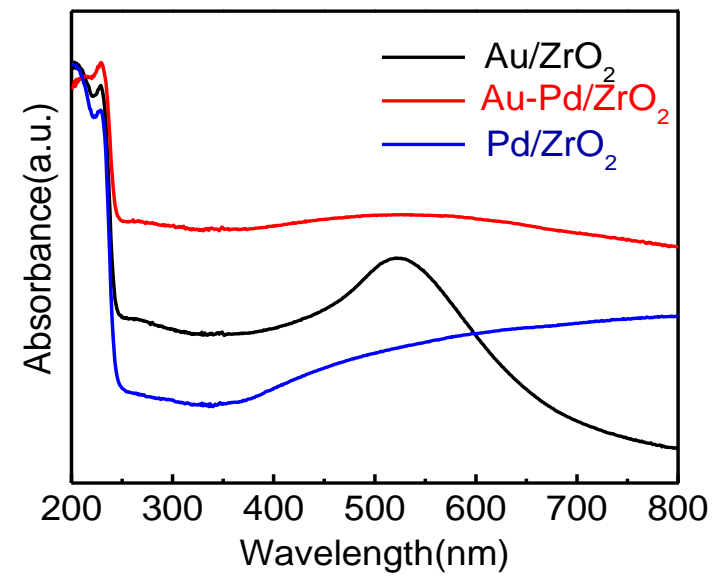

Fig. 4 Uv-vis absorption spectra of catalysts

\section{Summary}

In summary, the selective oxidation of benzyl alcohols to benzaldehydes on Au-Pd alloy NPs catalyst under mild conditions are highly effective. The significant enhancement of the catalytic activity of benzyl alcohol oxidation can be explained by the charge heterogeneity which is confirmed by DFT simulation results. Furthermore, the results of XPS and UV-Vis and XPS show that gold and palladium binary alloy formed on the $\mathrm{ZrO}_{2}$ and the catalyst is uniform and highly dispersed.

\section{References}

[1]. V.R. Choudhary, D.K. Dumbre, Appl. Catal., A. 375(2010) 252-257.

[2]. F. Gao, D.W. Goodman, Chem Soc Rev. 41(2012) 8009.

[3]. S. Marx, A. Baiker, J. Phys. Chem. C. 113(2009) 6191-6201.

[4]. H. Guo, M. Kemell, A. Al-Hunaiti, S. Rautiainen, M. Leskelä, T. Repo, Catal. Commun. 12 (2011) 1260-1264;

[5]. M. Sankar, E. Nowicka, R. Tiruvalam, Q. He, S. H. Taylor, C. J. Kiely, D. Bethell, D. W. Knight, G. J. Hutchings, Chem. Eur. J. 17 (2011) 6524-6532.

[6]. V. R. Choudhary, D. K. Dumbre, Appl. Catal. A. 375 (2010) 252-257;

[7]. S. Sarina, H. Zhu, E. Jaatinen, Q. Xiao, H. Liu, J. Jia, C. Chen, J. Zhao, J. Am. Chem. Soc. 135 (2013) 5793-5801

[8]. J. P. Roth, J. C. Yoder, T.-J. Won, J. M. Mayer, Science 294 (2001) 2524-2526. 